\title{
Chordal replacement with polytetrafluoroethylene sutures for mitral valve repair: A 25-year experience
}

Tirone E. David, MD, Susan Armstrong, MSc, and Joan Ivanov, PhD

Objective: The study objective was to examine the late results of mitral valve repair with chordal replacement with polytetrafluoroethylene sutures.

Methods: From 1986 to 2004, 606 consecutive patients with degenerative mitral regurgitation had mitral valve repair with chordal replacement with polytetrafluoroethylene sutures. Patients' mean age was 57 years, and $73.6 \%$ were men. Isolated prolapse of the anterior leaflet was present in $17.6 \%$ of patients, isolated posterior leaflet prolapse was present in $29.5 \%$ of patients, and bileaflet prolapse was present in $52.9 \%$ of patients. Prolapse was corrected by creating 2 to 38 neochords of polytetrafluoroethylene sutures (mean, $13 \pm 9$ per patient). The mean follow-up was 10.1 years, and $96 \%$ of the patients had multiple echocardiographic studies over the years.

Results: There were 5 early and 106 late deaths. Age, diabetes, hypertension, chronic obstructive lung disease, New York Heart Association functional classes III and IV, and ejection fraction less than $40 \%$ were independent predictors of mortality. At 18 years, freedom from reoperation on the mitral valve was $90.2 \% \pm 2.4 \%$, freedom from recurrent severe mitral regurgitation was $91.0 \% \pm 2.7 \%$, and freedom from moderate or severe mitral regurgitation was $67.5 \% \pm 4.2 \%$. Cox regression analysis revealed that isolated prolapse of the anterior leaflet was predictive of reoperation, and that older age, hypertension, and left ventricular ejection fraction less than $40 \%$ were predictive of recurrent moderate or severe mitral regurgitation.

Conclusions: Chordal replacement with polytetrafluoroethylene sutures expands the indication of repair to patients with prolapse of multiple segments. Valve function remains stable in most patients during the first 2 decades of follow-up. (J Thorac Cardiovasc Surg 2013;145:1563-9)

Chordal replacement during mitral valve (MV) repair has been performed since the early days of cardiac surgery, and materials such as silk, Teflon, nylon, strips of autologous, and glutaraldehyde-fixed bovine pericardium have been used. ${ }^{1-6}$ We first learned about the usefulness of expanded polytetrafluoroethylene (ePTFE) sutures to replace chordae tendineae at the Third International Symposium on Cardiac Bioprosthesis. Herbert Vetter, then a research fellow at Robert Frater's laboratory, presented "Replacement of Chordae Tendineae of the Mitral Valve Using the New Expanded PTFE Suture in Sheep."7 The results were impressive, and a few months later we began to use ePTFE sutures to reinforce flimsy and elongated chordae tendineae of the anterior leaflet of the MV that had been shortened during repair. ${ }^{8}$ As confidence in this material increased and further experimental evidence of its safety and effectiveness became available, ${ }^{9,10}$ we abandoned chordal shortening

\footnotetext{
From the Division of Cardiovascular Surgery of Peter Munk Cardiac Centre, Toronto General Hospital and University of Toronto, Toronto, Ontario, Canada. Disclosures: Authors have nothing to disclose with regard to commercial support. Received for publication March 3, 2012; revisions received April 15, 2012; accepted for publication May 15, 2012; available ahead of print June 19, 2012.

Address for reprints: Tirone E. David, MD, 200 Elizabeth St, 4N453, Toronto, Ontario M5G 2C4, Canada (E-mail: tirone.david@uhn.ca). $0022-5223 / \$ 36.00$

Copyright (c) 2013 by The American Association for Thoracic Surgery doi:10.1016/j.jtcvs.2012.05.030
}

and chordal transfer in favor of chordal replacement with ePTFE sutures. ${ }^{11}$ The operative technique evolved from using a single double-arm suture to replace each primary chorda by securing it to the papillary muscle and to the free margin of the leaflet, to creating multiple new chords with a single suture by successively passing once through the papillary muscle and twice through the free margin of the leaflet in such way as to have a neochord for every 2 to $3 \mathrm{~mm}$ of free margin of prolapsing leaflet, and tying the ends of the suture on the papillary muscle to leave the free margin free from the bulkiness of the knots. ${ }^{11,12}$ We have used ePTFE sutures to correct prolapse of both anterior and posterior leaflets. ${ }^{13}$

This study examines our clinical experience with MV repair using chordal replacement with ePTFE sutures during the past 25 years.

\section{PATIENTS AND METHODS}

The Research Ethics Board of the University Health Network approved this study. From January 1986 to December 2004, 928 consecutive patients underwent MV repair for mitral regurgitation (MR) due to degenerative disease of the MV by the senior author. Chordal replacement with ePTFE sutures was used in 606 of those patients. Table 1 shows the clinical characteristics of these 606 patients. Patients with combined aortic valve/root disease were included. Table 2 shows the operative data. The degree of myxomatous changes in the leaflets was graded as mild, moderate, and advanced degeneration. It was defined as "mild" when the leaflets were thin and had fairly normal sizes, and most segments were transparent except for the prolapsing area. This grading included Carpentier's "fibroelastic 


$$
\begin{aligned}
& \text { Abbreviations and Acronyms } \\
& \text { CI }=\text { confidence interval } \\
& \text { ePTFE }=\text { expanded polytetrafluoroethylene } \\
& \text { HR }=\text { hazard ratio } \\
& \text { MR }=\text { mitral regurgitation } \\
& \text { MV }=\text { mitral valve } \\
& \text { POD }=\text { postoperative day }
\end{aligned}
$$

deficiency" and cases with minimal myxomatous changes. Moderate degeneration was defined when the leaflets were opaque as the result of obvious myxomatous changes and the leaflet areas were increased but still somewhat elastic and not excessively thick $(<3 \mathrm{~mm})$. Advanced degeneration was defined when the leaflets were voluminous, aneurysmal, and thickened ( $\geq 3 \mathrm{~mm}$ ), and the annulus was massively dilated and often displayed posterior displacement of $5 \mathrm{~mm}$ or more. ${ }^{14}$ The prolapse of the leaflets was classified as anterior, posterior, or bileaflet. A few cases of isolated commissural prolapse were classified as bileaflet prolapse. Combined aortic valve/root disease was present in 24 of 106 patients (22.6\%) with isolated anterior leaflet prolapse, 14 of 179 patients $(7.8 \%)$ with isolated posterior leaflet prolapse, and 26 of 321 patients $(8.1 \%)$ with bileaflet prolapse $(P=.0001)$.

Prolapse of the anterior leaflet and the commissural areas was always corrected by chordal replacement with ePTFE sutures. Prolapse of the posterior leaflet was corrected with ePTFE sutures when the leaflet was normal in size or only slightly increased in height $(\mathrm{eg},<20 \mathrm{~mm})$ and by partial resection when its height was $20 \mathrm{~mm}$ or more to shorten to approximately $15 \mathrm{~mm}$. Patients with severe annular displacement had the entire posterior leaflet detached from the annulus, shortened, and reattached to the endocardium of the left ventricle where the annuloplasty sutures were applied. ${ }^{14}$ ePTFE chords were often needed to correct the residual prolapse of this sliding plasty and reduction in posterior leaflet height.

Prolapse of the leaflets was corrected by creating numerous new chords of 5-0 or 6-0 ePTFE sutures between the papillary muscle and the free margin of the leaflet. An ePTFE suture was secured to the papillary muscle and then successively passed twice through the free margin of the leaflet and once through a fibrous portion of the papillary muscle to create 4 to 6 pairs of chords per suture for a total of 8 to 12 neochords. Each chord was approximately 2 to $3 \mathrm{~mm}$ apart depending on the thickness of the leaflet at the free margin to minimize the load in each one. ${ }^{15}$ Thus, a single suture anchored 10 to $15 \mathrm{~mm}$ of the leaflet's free margin. The length of each chord was estimated on the basis of the coaptation level of a normal segment. When every segment was prolapsing, we used the level of the mitral annulus as the reference point in the arrested, relaxed heart. Because most neochords were interdependent, final adjustment of length probably occurred spontaneously after discontinuation of cardiopulmonary bypass. The number of neochords implanted ranged from 2 to 38, with a mean of $13 \pm 9$ chords per repaired valve. Patients received warfarin sodium postoperatively for the first 3 postoperative months and permanently if they were in atrial fibrillation.

Patients have been contacted every second year, and an echocardiogram was obtained to assess valve and ventricular function. Approximately one half of all echocardiograms were performed at outside institutions, and their reports were entered into our database. The follow-up for this study was closed on June 30,2011 . The mean follow-up was $10.1 \pm 4.5$ years (range, 0-23 years). All patients had at least 1 postoperative transthoracic echocardiogram, and $96 \%$ of patients had multiple studies. The mean echocardiographic study follow-up was $9.4 \pm 4.5$ years (range, 0-22.6 years).

\section{Statistical Analyses}

All data analysis was performed using SAS software, version 9.2 for Windows (SAS Institute, Inc, Cary, NC). Descriptive statistics were used for continuous variables, including mean, median, standard deviation, and standard error. Frequencies were used for categoric variables. Univariate comparisons included unpaired $t$ tests and analysis of variance for continuous variables, contingency table analysis for categoric variables, and Kaplan-Meir analysis for time-to-event outcomes. Cox multiple regression analysis was performed to identify independent predictors of time-to-event outcomes by entering all variables that had a univariate association with each outcome at $P$ less than .25 or those of known clinical significance but failing to meet the critical alpha level for submission to the model. Variables entered included age per 5-year increment, female gender, diabetes, hypertension, congestive heart failure, peripheral vascular disease, chronic obstructive lung disease, renal insufficiency, New York Heart Association functional classes III and IV, left ventricular dysfunction (ejection fraction $<40 \%$ ), coronary artery disease, degree of myxomatous degeneration, leaflet prolapsed, concomitant aortic valve surgery, aortic arch surgery, and urgent priority. The alpha for statistical significance was 0.05 .

\section{RESULTS \\ Operative Mortality and Morbidity}

Five patients died in hospital, and autopsy was performed in all 5. The causes of death were acute left ventricular outflow tract obstruction caused by partial dehiscence of the inflow suture of an aortic homograft in 1 patient on postoperative day (POD) 1; acute type A dissection in 1 patient on POD 6; volvulus with peritonitis, sepsis, and multiorgan failure on POD 12 in 1 patient; ventricular fibrillation on POD 7 after a perioperative myocardial infarction in 1 patient, and pneumonia at a convalescence hospital on POD 51 in 1 patient. Two patients had perioperative myocardial infarction, 4 patients had stroke, and 19 patients had low cardiac output syndrome and required inotropes ( 5 of them had an intra-aortic balloon pump). Early reoperation was necessary for bleeding in 23 patients, cardiac tamponade in 2 patients, cardiac arrest in 1 patient, sternal infection in 1 patient, and MV re-repair for medically intractable systolic anterior motion of the anterior leaflet of the MV with MR in 1. Early postoperative atrial fibrillation occurred in 236 patients (39\%).

\section{Late Mortality}

There were 106 late deaths: valve- or cardiac-related in 52 patients, other causes in 53 patients, and unknown cause in 1 patient. The causes of valve- or cardiac-related deaths were anticoagulation-related hemorrhage in 10 patients, stroke in 6 patients, congestive heart failure in 12 patients (due to ventricular dysfunction in 9 and recurrent MR in 3), sudden death in 12 patients, myocardial infarction in 9 patients, after cardiac surgery for coronary artery disease in 1 patient, aortic valve disease in 1 patient, and recurrent MR in 1 patient. Table 3 shows the variables predictive of mortality from any cause by Cox regression analysis. 
TABLE 1. Clinical characteristics of 606 patients

\begin{tabular}{|c|c|}
\hline Age $($ mean \pm SD) & $57.2 \pm 13.3 \mathrm{y}$ \\
\hline Range & $18-88$ y \\
\hline Male sex & $446(73.6)$ \\
\hline \multicolumn{2}{|l|}{ Electrocardiogram } \\
\hline Sinus rhythm & 477 (78.6) \\
\hline Atrial fibrillation & $129(21.3)$ \\
\hline \multicolumn{2}{|l|}{ Associated diseases } \\
\hline Hypertension & $161(26.5)$ \\
\hline Previous stroke & $37(6.1)$ \\
\hline Diabetes & $21(3.4)$ \\
\hline Peripheral vascular disease & 3 \\
\hline Renal failure & 4 \\
\hline COPD $\left(\mathrm{FEV}_{1}<1 \mathrm{~L} / \mathrm{sec}\right)$ & $22(3.6)$ \\
\hline Remote infective endocarditis & $56(9.2)$ \\
\hline Active infective endocarditis & 2 \\
\hline \multicolumn{2}{|l|}{ NYHA functional class } \\
\hline 1 and 2 & $331(54.6)$ \\
\hline 3 and 4 & $275(45.4)$ \\
\hline \multicolumn{2}{|l|}{ LVEF } \\
\hline$\geq 40 \%$ & $570(94)$ \\
\hline$<40 \%$ & $36(6)$ \\
\hline Aortic valve/root disease & $64(10.5)$ \\
\hline Tricuspid insufficiency $>2+$ & $22(3.6)$ \\
\hline Coronary artery disease & $91(15.0)$ \\
\hline
\end{tabular}

\section{Patients' Survival}

Survival for all patients at 1,10 , and 18 years was $98.1 \%$ $\pm-0.5 \%, 85.7 \% \pm 1.5 \%$, and $66.8 \% \pm 3.3 \%$, respectively. Figure 1 shows Kaplan-Meier estimates of survival of the entire cohort and of patients in New York Heart Association functional classes 1 and 2 versus 3 and 4 .

\section{Thromboembolic Complications}

Thirty patients had 1 or more episodes of transient ischemic cerebral attacks, and 31 patients had a stroke (6 died). The freedom from thromboembolic events at 1, 10, and 18 years was $96.8 \% \pm 0.7 \%, 90.3 \% \pm 0.9 \%$, and $81.6 \% \pm 3.6 \%$, respectively.

\section{Endocarditis}

Infective endocarditis developed in 5 patients; 2 required reoperation, and 3 were treated with antibiotics alone. All patients survived.

Reoperations. Reoperations on the MV were performed in 35 patients. The indication for reoperation was recurrent MR in 25 patients, hemolysis in 4 patients, mitral stenosis in 3 patients (pannus in 2 and fibrosis and calcification of the leaflets in 1), endocarditis in 2 patients, and systolic anterior motion of the anterior leaflet of the MV in 1 patient. The MV was replaced in 32 patients and re-repaired in 3 patients. Reoperations were performed 1 week to 22.6 years
TABLE 2. Operative data

\begin{tabular}{lc}
\hline Degree of myxomatous changes & \\
$\quad$ None or mild & $181(29.8)$ \\
Moderate & $248(40.9)$ \\
Advanced & $177(29.2)$ \\
Mitral leaflet prolapse & \\
AL prolapse & $106(17.4)$ \\
PL prolapse & $179(29.5)$ \\
Bileaflet prolapse & $321(52.9)$ \\
Mitral annuloplasty & \\
None & $32(5.2)$ \\
Carpentier ring & $52(5.2)$ \\
Duran ring & $116(19.1)$ \\
Cosgrove band & $406(66.9)$ \\
Reconstruction of the mitral annulus & $13(3)$ \\
Tricuspid valve repair & $22(3.6)$ \\
Maze procedure for atrial fibrillation & $17(2.8)$ \\
Aortic valve repair \pm RAA & $13(2.1)$ \\
Aortic valve sparing & $35(5.7)$ \\
Bentall procedure & $6(1.0)$ \\
Aortic valve replacement + RAA & $10(1.6)$ \\
Coronary artery bypass & $91(15)$ \\
Cardiopulmonary bypass time (mean \pm SD) min & $90 \pm 30$ \\
Aortic clamping time (mean \pm SD) min & $72 \pm 25$
\end{tabular}

Percentages are shown in parentheses. $A L$, Anterior leaflet; $P L$, posterior leaflet; $R A A$, replacement of the ascending aorta; $S D$, standard deviation.

after surgery. Reoperations were performed at Toronto General Hospital in 33 patients with no operative mortality and elsewhere in 2 patients with 1 death. A review of the preoperative echocardiograms and operative reports on 33 patients who underwent operation at Toronto General Hospital indicated that 2 patients had infective endocarditis with destruction of the leaflets and the MV was replaced; 4 patients had hemolysis due to MR after complex MV repair, including reconstruction of the mitral annulus because of dystrophic calcification in 2 patients, and re-repair was attempted but because there was residual MR, the MV was replaced in all 4 patients; late mitral stenosis due to pannus or calcification of the leaflets developed in 3 patients, and the MV was replaced; 1 patient had medically intractable systolic anterior motion of the MV, and the MV was re-repaired, and 23 patients had late MR that was due to prolapse of 1 or more previously normal segments in 11 patients (9 had replacement and 2 had re-repair), fibrosis and calcification of the anterior leaflet in 8 patients (all had replacement), dehiscence of a rigid annuloplasty ring and prolapse in 1 patient, ruptured papillary muscle due to myocardial infarction in 1 patient, tethering of the leaflets due to ventricular dysfunction and dilation in 1 patient, and detachment of the ePTFE chords from papillary muscle in 1 patient (all 4 had replacement). In addition, the aortic valve or root was replaced at the same time in 5 patients, and the tricuspid valve was repaired in 4 patients. The only predictor of reoperation by Cox regression analysis was isolated 
TABLE 3. Predictors of mortality (all causes) by Cox regression analysis

\begin{tabular}{lccc}
\hline \multicolumn{1}{c}{ Parameter } & HR & $\mathbf{9 5} \%$ CI & $\boldsymbol{P}$ value \\
\hline Age by 5-y increments & 1.40 & $1.26-1.56$ & .000 \\
Diabetes & 2.24 & $0.97-5.16$ & .058 \\
Hypertension & 1.60 & $1.09-2.35$ & .016 \\
COPD & 2.41 & $1.31-4.42$ & .004 \\
NYHA class 3 and 4 & 2.02 & $1.28-3.19$ & .002 \\
Ejection fraction $<40 \%$ & 4.57 & $2.70-7.74$ & .000 \\
\hline
\end{tabular}

$H R$, Hazard ratio; $C I$, confidence interval; $C O P D$, chronic obstructive pulmonary disease; NYHA, New York Heart Association.

prolapse of the anterior leaflet (hazard ratio [HR], 2.56; $95 \%$ confidence interval $[\mathrm{CI}], 0.99-6.63 ; P=.052)$. The degree of myxomatous degeneration had no effect on the risk of reoperation by multivariate analysis. The freedom from reoperation on the MV at 1,10 , and 18 years was $98.6 \%$ $\pm-0.4 \%, 94.7 \% \pm-0.9 \%$, and $90.2 \% \pm 2.4 \%$, respectively (Figure 2). The freedom from reoperation according to which leaflet had prolapse is shown in Figure 3. In addition to the MV reoperations, 1 patient had coronary artery bypass and 1 patient had aortic valve replacement, but nothing was done to the MV because it was functioning normally.

Recurrent mitral regurgitation. The latest echocardiogram before death, reoperation, or follow-up contact showed that severe MR developed in 22 patients (10 underwent reoperation, 8 died but only 1 of MR, and 4 were alive) and moderate MR developed in 60 patients ( 9 underwent reoperation, 13 died but only 1 of MR, and 38 were alive). The following variables were predictive of recurrent moderate or severe MR by Cox regression analysis: age by 5 -year increments (HR, $1.21 ; 95 \% \mathrm{CI}, 1.10-1.34 ; P=.0001)$, hypertension (HR, 1.82; 95\% CI, 1.13-2.94; $P=.013$ ), and left ventricular ejection fraction less than $40 \%$ (HR, 4.72; 95\% CI, 2.54-8.77; $P=.0001)$. Recurrent MR was more

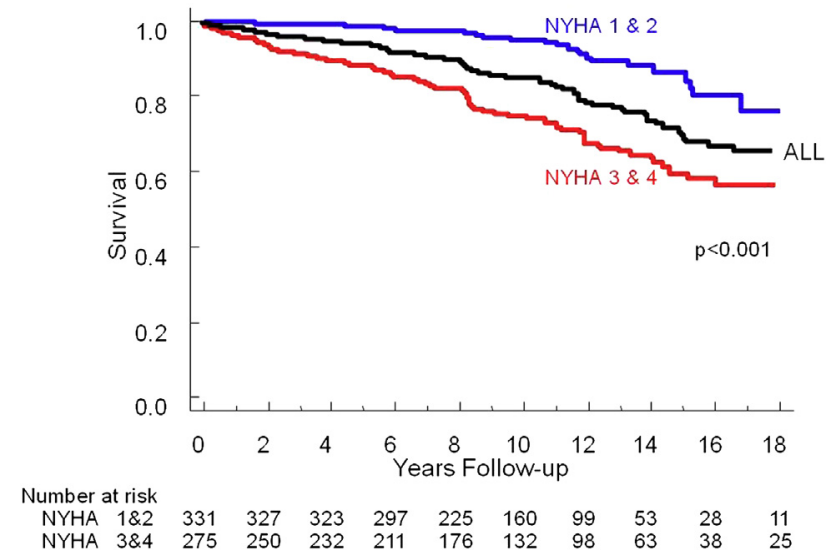

FIGURE 1. Patients' survival: Overall and according to functional class. NYHA, New York Heart Association.

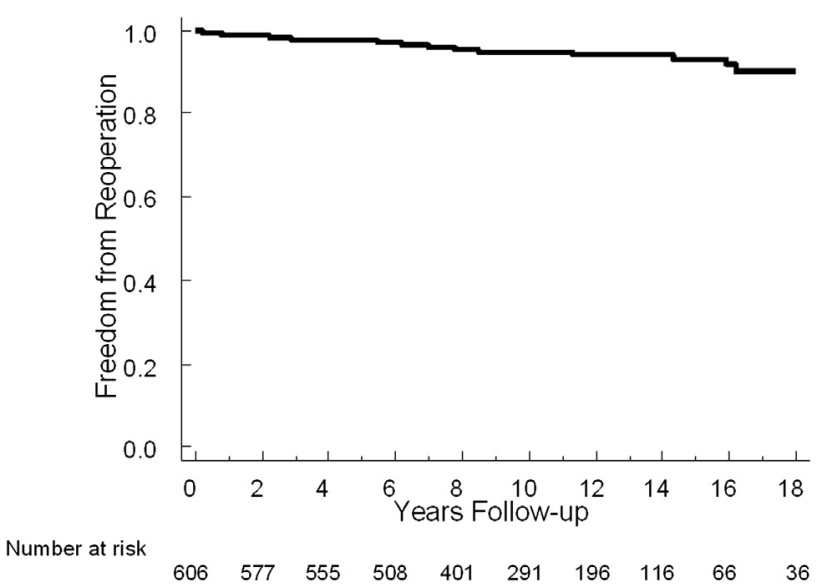

FIGURE 2. Freedom from reoperation on the MV.

common among patients with advanced myxomatous degeneration, anterior leaflet prolapse, and bileaflet prolapse by univariate analysis but not by multivariate analysis. Freedom from severe MR at 1, 10, and 18 years was $100 \%$, $96.5 \% \pm-0.8 \%$, and $91.0 \% \pm 2.7 \%$, respectively. Freedom from moderate or severe MR at 1,10 , and 18 years was $98.5 \% \pm 0.4 \%, 87.8 \% \pm 1.5 \%$, and $67.5 \% \pm$ $4.2 \%$, respectively. Figure 4 shows the Kaplan-Meier estimates of freedom from moderate or severe recurrent MR.

\section{Oral Anticoagulation}

A total of 130 patients were taking an oral anticoagulant at the time of latest follow-up: 20 for previous thromboembolic event (stroke in 11 and transient ischemic attacks in 9) and 58 for atrial dysrhythmias (fibrillation in 50 and flutter in 8). In the remaining 52 patients, 12 had a permanent pacemaker and 40 were in sinus rhythm. A total of 20 of 130 patients taking oral anticoagulation experienced major bleeding, and 12 patients died.

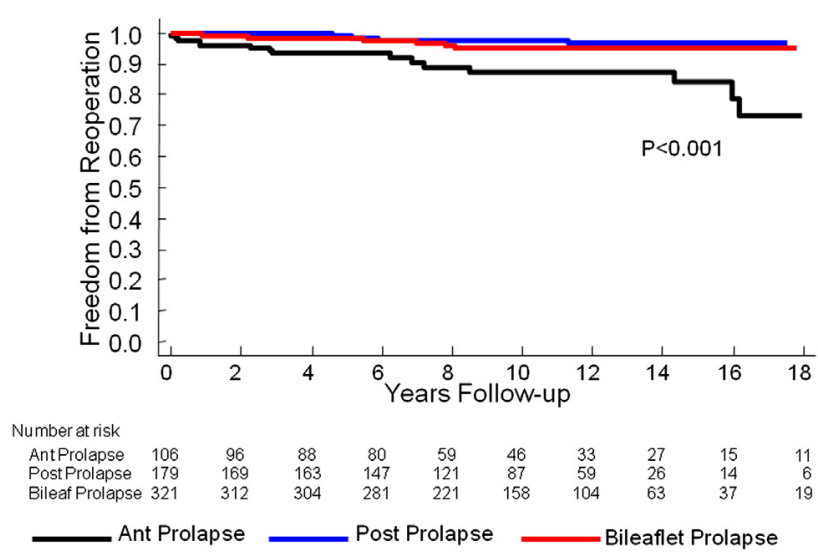

FIGURE 3. Freedom from reoperation on the MV according to leaflet prolapse. 


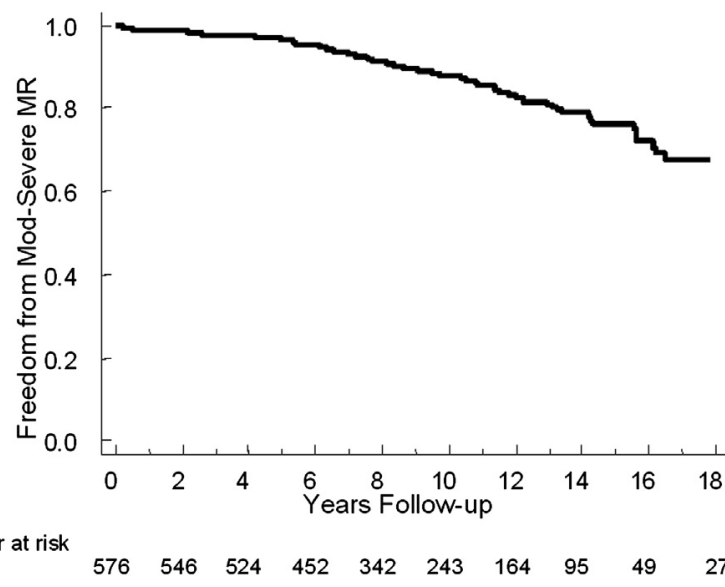

FIGURE 4. Freedom from recurrent moderate or severe MR. MR, Mitral regurgitation.

\section{Electrocardiogram}

Electrocardiograms were available in 574 patients during the follow-up; 416 were in sinus rhythm, 122 in atrial fibrillation or flutter, and 36 had paced beats.

\section{Functional Class}

At the time of the latest follow-up contact, 462 patients were alive with their native MV; $328(71 \%)$ were in functional class I, $94(20.3 \%)$ were in class II, $39(8.4 \%)$ were in class III, and $1(0.2 \%)$ was in class IV.

\section{DISCUSSION}

ePTFE sutures are now frequently used to replace elongated or ruptured chordae tendineae during MV repair and to correct prolapse of the tricuspid valve leaflets due to chordal elongation caused by degenerative disease or papillary muscle rupture secondary to myocardial infarction or trauma. We initially used ePTFE suture to correct prolapse of the anterior leaflet of the MV, but by 1990 we began using it to repair prolapse of the posterior leaflet and the commissures and progressively reduced use of Carpentier's techniques of leaflet resection, chordal shortening, and chordal transfer particularly in patients with normal or minimally enlarged leaflets, such as those with fibroelastic deficiency or mild myxomatous changes. Chordal replacement with ePTFE suture allowed us to increase the MV repair rate to $95 \%$ of patients with MR due to degenerative disease. ${ }^{13} \mathrm{We}$ do not believe that there is a contraindication to the use of ePTFE sutures to replace chordae tendineae, and replacement of the MV is performed only in older patients with advanced myxomatous degeneration of the entire valve with thickened and fibrotic leaflets. Dystrophic calcification of the mitral annulus is not a contraindication to MV repair if the leaflets are pliable. It is usually treated by resection of the calcium bar, reconstruction of the mitral annulus with pericardial substitutes, reattachment of the posterior leaflet to the reconstructed annulus, and correction of leaflet prolapse with neochords of ePTFE.

Our operative technique of chordal replacement has evolved over the years. We initially replaced each ruptured or elongated primary chorda individually with a doublearm 4-0 ePTFE suture by securing it to a fibrous portion of the papillary muscle and then by passing it through the free margin of the prolapsing leaflet and tying the ends together on the ventricular side of the leaflet. ${ }^{8}$ As better understanding of the biomechanical properties of ePTFE sutures became known ${ }^{16}$ and our clinical experience increased, we began to use larger number of neochords per centimeter of prolapsing free margin to minimize the mechanical stress on each neochord and on the leaflet where it was attached. ${ }^{12}$ This newer approach allowed the repair of valves with prolapse of multiple segments and maintained a relatively low operative time.${ }^{14}$ During the past 15 years, only 6-0 and 5-0 ePTFE sutures have been used for mitral and tricuspid valve repair. As described in our previous publications, ${ }^{12-14}$ we first secure the ePTFE suture on the papillary muscle; then the longer arm of the suture is successively passed twice through the free margin of the leaflet and once through a fibrous portion of the papillary muscle and then back in the free margin and so forth. The first and last loops of neochord are usually attached to nonprolapsing segments of the valve. A single suture is often used to create 4 to 6 pairs of neochords. Each neochord anchors only 2 to $3 \mathrm{~mm}$ of free margin. This approach explains the relatively high number of neochords we have used in our patients. We have not documented neochord rupture but had 1 case of detachment of the neochords from papillary muscle in our experience with 33 patients who underwent reoperation at Toronto General Hospital.

Although chordal replacement with ePTFE sutures is particularly useful in patients with prolapse of multiple segments, such as in advanced myxomatous degeneration of the MV, it is also useful in patients with fibroelastic deficiency with isolated prolapse of the posterior leaflet in whom the leaflets are relatively normal and resection would be associated with reduction of the MV orifice. We did not perform mitral annuloplasty in 32 patients with fibroelastic deficiency in whom the annulus was too small to be further reduced and repair was accomplished by correcting the leaflet prolapse alone. The current trend is to avoid leaflet resection altogether and use only neochords to correct leaflet prolapse. ${ }^{16-18}$ Some investigators believe that a nonresectional approach during MV repair has less deleterious effects on the movements of the mitral annulus and on posterior leaflet mobility soon after surgery. ${ }^{19}$ In our experience, flexible bands and rings 
become rigid within a few years after implantation. We favor posterior flexible bands over complete rings in patients with normal ventricular function because that is where the mitral annulus dilates in patients with degenerative disease. $^{20}$

Our patients who underwent MV repair with chordal replacement with ePTFE sutures do not represent a "general" population of patients with MR due to degenerative disease because of referral bias and they underwent operation as much as 25 years ago. Approximately one third of our patients had advanced myxomatous degeneration of the MV, $3 \%$ of patients had dystrophic calcification of the mitral annulus, and only $29 \%$ of patients had isolated prolapse of the posterior leaflet. In a recent report from Italy on chordal replacement with EPTFE sutures, more than one half of the patients had isolated prolapse of the posterior leaflet. ${ }^{21} \mathrm{In}$ addition, we included patients who had aortic root or valve operation. The proportion of patients who had a concomitant Maze procedure for atrial fibrillation was low largely because we did not routinely perform this procedure before this millennium and most patients in this series underwent operation before that. We also had a small number of patients who required concomitant tricuspid valve repair, although we believe that moderate and severe tricuspid regurgitation should be corrected at the time of MV surgery. There is evidence that mild tricuspid regurgitation does not need to be addressed at the time of MV repair for degenerative disease. ${ }^{22}$ The low incidence of tricuspid regurgitation in our series could be explained by the fact that more than one half of the patients were asymptomatic or had minimal symptoms and underwent operation early in the course of the MR.

The main purpose of the study was to examine the durability of MV repair when ePTFE was used to correct prolapse of the leaflets. Although the freedom from reoperation was low, recurrent MR after MV repair is common in patients with degenerative disease, particularly in patients with isolated prolapse of the anterior leaflet. We were surprised to find that the degree of myxomatous degeneration on the leaflets and the number of segments with prolapse had no effect on the risk of reoperation or late recurrent MR. This is possibly due to our liberal use of neochords to anchor the prolapsing segments. However, this approach has not solved the problem of isolated anterior leaflet prolapse, which was associated with a higher risk of reoperation than with posterior or bileaflet prolapse. We could not find a good explanation for the finding, but most patients with recurrent MR and corrected prolapse of the anterior leaflet had concomitant aortic valve disease. These patients often have larger than normal anterior leaflets. ${ }^{23}$

The main indication for reoperation in our patients was recurrent MR, but re-repair was feasible in only a few patients because the degenerative process progressed and the leaflets became thickened, fibrotic, and sometimes even calcified in most patients who underwent reoperation. Several patients were found to have severe or moderate recurrent MR at the time of last follow-up contact and are being evaluated for reoperation. Although we do offer surgery to asymptomatic patients with severe MR in whom MV repair is likely, we tend to be more conservative in those with asymptomatic recurrent MR because in our experience only a small proportion can undergo satisfactory rerepair.

\section{Study Limitations}

This is a retrospective, observational study of patients who underwent MV repair with chordal replacement with ePTFE sutures performed by a single surgeon, and the results may not be generalizable. The technique used to replace chordae tendineae changed during the study to allow us to expand the indications of MV repair to patients with more extensive leaflets prolapsed, and this may have had adversely affected the durability of the repair. Approximately one half of all follow-up echocardiograms were performed at multiple institutions, and the interpretation of the results may have been different if analyzed by a central laboratory. Associated aortic valve disease also may have affected the long-term outcomes, and the proportion was too small for meaningful analysis.

\section{CONCLUSIONS}

This study showed that chordal replacement with ePTFE sutures allowed MV repair in patients with complex pathologies, such as advanced myxomatous degeneration with prolapse of multiple segments. The long-term results are satisfactory, but recurrent moderate or severe MR developed in approximately one third of the patients at 18 years after surgery largely because of progression of the degenerative process.

\section{References}

1. January LE, Fisher JM, Erhenhaft JL. Mitral insufficiency resulting from rupture of normal chordae tendineae. Report of a surgically corrected case. Circulation. 1962;26:1329-33

2. Kay JH, Egerton WS. The repair of mitral insufficiency associated with ruptured chordae tendineae. Ann Surg. 1963;157:351-60.

3. Morris JD, Penner DA, Brandt RL, Arbor A. Surgical correction of ruptured chordae tendineae. J Thorac Cardiovasc Surg. 1964;48:772-80.

4. Marchand P, Barlow JB, Du Plessis LA, Webster I. Mitral regurgitation with rupture of normal chorea tendineae. Br Heart J. 1966;28:746-58.

5. Rittenhouse EA, David CC, Wood SJ, Sauvage LR. Replacement of ruptured chordae tendineae of the mitral valve with autologous pericardial chordae. J Thorac Cardiovasc Surg. 1978;75:870-6.

6. Frater RWM, Gabbay S, Shore D, Factor S, Strom J. Reproducible replacement of elongated or ruptured chordae mitral valve chordae. Ann Thorac Surg. 1983; 35:14-28.

7. Vetter HO, Burack JH, Factor SM, Malacuso F, Frater RWM. Replacement of chordae tendineae of the mitral valve using the new expanded PTFE suture in sheep. In: Bodnar E, Yacoub M, eds. Biologic and Bioprosthetic Valves. New York: Yorke Medical Books; 1986:772-85.

8. David TE. Replacement of chordae tendineae with expanded polytetrafluoroethylene sutures. J Cardiac Surg. 1989;4:286-90. 
9. Revuelta JM, Garcia-Rinaldi R, Gaite L, Val F, Garijo F. Generation of chordae tendineae with polytetrafluoroethylene stents. Results of mitral valve chordal replacement in sheep. J Thorac Cardiovasc Surg. 1989;97:98-103.

10. Zussa C, Frater RW, Polesel E, Galloni M, Valfré C. Artificial mitral valve chordae: experimental and clinical experience. Ann Thorac Surg. 1990;50: 367-73.

11. David TE, Omran A, Armstrong S, Xun Z, Ivanov J. Long-term results of mitral valve repair for myxomatous disease with and without chordal replacement with expanded polytetrafluoroethylene sutures. J Thorac Cardiovasc Surg. 1998;115: 1279-86.

12. David TE. Artificial chordae. Semin Thorac Cardiovasc Surg. 2004;16:161-8.

13. David TE, Ivanov J, Armstrong S, Christie D, Rakowski H. A comparison of outcomes of mitral valve repair for degenerative disease with posterior, anterior, and bileaflet prolapse. J Thorac Cardiovasc Surg. 2005;130:1242-9.

14. Newcomb AE, David TE, Lad VS, Bobiarski J, Armstrong S, Maganti M. Mitral valve repair for advanced myxomatous degeneration with posterior displacement of the mitral annulus. J Thorac Cardiovasc Surg. 2008;136:1503-9.

15. Reimink MS, Kunzelman KS, Verrier ED, Cochran RP. The effect of anterior chordal replacement on mitral valve function and stresses. A finite element study. ASAIO J. 1995;41:M754-62.

16. Seeburger J, Falk V, Borger MA, Passage J, Walther T, Doll N, et al. Chordae replacement versus resection for repair of isolated posterior mitral leaflet prolapse: à ègalité. Ann Thorac Surg. 2009;87:1715-20.
17. Lange R, Guenther T, Noebauer C, Kiefer B, Eichinger W, Voss B, et al. Chordal replacement versus quadrangular resection for repair of isolated posterior mitral leaflet prolapse. Ann Thorac Surg. 2010;89:1163-70.

18. Lawrie GM, Earle EA, Earle N. Intermediate-term results of a nonresectional dynamic repair technique in 662 patients with mitral valve prolapse and mitral regurgitation. J Thorac Cardiovasc Surg. 2011;141:368-76.

19. Ben Zekry S, Lang RM, Sugeng L, McCulloch ML, Weinert L, Raman J, et al. Mitral annulus dynamics early after valve repair: preliminary observations of the effect of resectional versus non-resectional approaches. Am Soc Echocardiogr. 2011;24:1233-42.

20. Suri RM, Grewal J, Mankad S, Enriquez-Sarano M, Miller FA Jr, Schaff HV. Is the anterior intertrigonal distance increased in patients with mitral regurgitation due to leaflet prolapse? Ann Thorac Surg. 2009;88:1202-8.

21. Salvador L, Mirone S, Bianchini R, Regesta T, Patelli F, Minniti G, et al. A 20-year experience with mitral valve repair with artificial chordae in 608 patients. J Thorac Cardiovasc Surg. 2008;135:1280-7.

22. Yilmaz O, Suri RM, Dearani JA, Sundt TM 3rd, Daly RC, Burkhart HM, et al Functional tricuspid regurgitation at the time of mitral valve repair for degenerative leaflet prolapse: the case for a selective approach. $J$ Thorac Cardiovasc Surg. 2011;142:608-13.

23. Lad V, David TE, Vegas A. Mitral regurgitation due to myxomatous degeneration combined with bicuspid aortic valve disease is often due to prolapse of the anterior leaflet of the mitral valve. Ann Thorac Surg. 2009;87:79-82. 